\title{
Moving on up: Women in healthcare leadership
}

While the number of female GPs is steadily increasing, more managerial positions are still held by men. Is general practice at risk of taking on a 'macho' management culture? What are the opportunities for female leaders in primary care?

Judith Smith

Professor of Health Policy and Management; Director, Health Services Management Centre, University of Birmingham

Jennifer Gosling Assistant Professor in Management, Department of Health Services Research and Policy, London School of Hygiene \& Tropical Medicine

In recent years, increasing attention has rightly (and belatedly) been paid to the need for greater diversity in the leadership and management community of the NHS. The Health Service Journal has undertaken regular analysis of NHS management demography and formed a women leaders' network; Roger Kline has written powerfully of the 'snowy white peaks' of the NHS, where people of black and minority ethnic (BME) backgrounds are woefully under-represented on boards and in senior management roles; and the NHS Leadership Academy has embedded diversity and inclusion as a central element of its programmes and other support offers.1-3

Much of the debate about the composition of the NHS leadership and management population is, however, implicitly focused on those who work in NHS Trusts and Foundation Trusts, and much less often on primary care, whether general practice, community pharmacy, optometry or dentistry. Primary care services are where the vast majority of NHS care contacts take place each day; yet relatively little attention is paid to the composition and support of the management and leadership community charged with keeping these hard-pressed and often isolated care organisations running, and ensuring they are fit for the future.

\section{The leadership challenge}

The case of general medical practice is particularly instructive in relation to the experience of women in leadership and management in primary care, the roles they typically assume (or do not) and the reasons that appear to underpin such patterns. June Huntington was one of the first academics to undertake indepth study of the management of general practice. She identified two main aspects: 'clinical work', led by GPs and 'practice management', undertaken by administrative staff. In 1995, when she published her work, these groups were highly gendered, with a majority of GP leaders at practice, district and national level being male, and almost all practice managers being female.4,5

Given that 52\% of GPs in England are now female, an examination of the current experience of women GP leaders and practice managers enables important issues to be explored that resonate with the wider concern about diversity and inclusion in NHS management.6 The management and leadership challenge in general practice has grown in size and complexity in recent years. Practices are typically larger; 7 services such as chronic disease management have been moved from hospital to primary care settings; care teams include a wider range of health professionals; IT and technology play a greater role in the administration and support of care; external regulation has mushroomed; and general practice is part of wider networks or federations for the purpose of both commissioning and provision.

The demography of general practice has seen a sustained change over the past two decades. Women GPs formed 35\% of the total in England in 2002 and, by 2016, this had grown to 52\%.6 Partly linked to this feminisation of general practice (but also to the preferences of 'generation $X$ and $Y$ ' trainees) has been the growth in sessional and salaried GPs to reach a third in 2013, meaning that the traditional partnership owner-operator model of general practice appears to be in decline.7 


\section{Gender shift}

Given this relatively rapid change in the gender and employment status composition of general practice, it would be reasonable to expect that there would have been a similar shift in the gender balance of leadership roles, such as senior partners of practices, chairs or accountable officers of clinical commissioning groups (CCGs), chairs of local medical committees, lead GPs of federations and superpartnerships, and holding national representative roles.

The data are not, however, encouraging in this regard. While we now have the third consecutive woman Chair of the Royal College of GPs, the proportion of female GP leads in CCGs (those who lead a CCG workstream) in 2015 was 26\%; 37\% of CCG governing members were women and 29 CCGs had no female GP leads at all.8 We were not able to locate data for the gender breakdown of leaders of 'at scale' primary care organisations such as GP federations and super-partnerships, although we suspect that, again, more of these positions are held by men. It would seem that the peaks of general practice continue largely to be scaled by male GPs who are more likely to be working as practice partners, making it less likely that the model of GP leadership will change to one that is more amenable to, and reflective of, GPs who are women and/or choose to work on a sessional, salaried or part-time basis.

The rising concern about pressures in and on general practice, and calls for the profession to stand back and plan new models of care and business to enable primary care to be fit for the future, mean that a significant shift in the nature, diversity and role of GP leadership is overdue. This will likely involve a challenge to some sacred cows of general practice, including the partnership model and ownership of premises; but there is also the opportunity to craft a new approach that embraces greater flexibility of working practices, more diverse career paths, and the opportunity to specialise within general practice, and to assume a new range of management and leadership roles. 9

\section{General practice}

Practice management starts from a different place from general medical practice; namely, of having been almost completely dominated by women in the 1980s and 1990s, but now shifting to three-quarters female by 2015. We can also hypothesise from available data that this shift is happening more in larger general practice organisations, where men appear to be assuming more senior and complex primary care management roles that are appearing as federations, super-partnerships and other 'at scale' organisations take shape. This mirrors the evidence that, in 2015, 36\% of NHS Trust chief executives were women; but if we look behind the statistics, these posts are concentrated more in areas such as community health, mental health services or children's and women's services, and less in the leadership of large acute Trusts.10 This reflects well-documented research into gender and organisation, which tells us that women will tend to be found in greater numbers in those parts of a profession or sector deemed to be less powerful or attractive.11 Just as practice and primary care management appears to be taken more seriously - with new and more senior posts emerging in federations, networks, CCGs and superpartnerships - so it appears that men are choosing to move into such roles, as was also noted with GP fundholding in the 1990s.12

The gender pay gap is in evidence in practice management, with women practice managers paid less than men. In 2000, the gender pay gap among practice managers was $£ 5,000$ per year and, in the most recent annual survey of practice managers' pay in 2016 , it was $£ 4,000$ per year. 13

This leads us to question whether general practice, as it increases in size and complexity, is at risk of taking on the more macho management culture of the wider NHS; one that has been criticised as being harmful to both staff and patients.14 This shift may already be deterring women (and, indeed, some men) from entering or staying in the profession, and be impeding the creation of a more distributed, kinder and appropriate management culture. 
Here, we see the dilemmas of general practice leadership and practice management converging. In both cases, the management task is growing and becoming more complex and challenging; and yet the roles are not being crafted in a way that makes them attractive to (at least some) women. This leaves the way open to more of the same in relation to primary care management and leadership - mainly male GP partners and increasing numbers of senior male primary care managers - when there is an opportunity to create new forms of leadership along with the 'transformation' of primary care that is so often vaunted in policy circles.

\section{Future research}

Our analysis is, in part, speculation based on the wider literature and research into gender and organisation where practice managers are concerned, for there has been woefully little research into practice managers as a profession, and especially in comparison with women in medicine. This gap will start to be addressed by new research that has been funded by the Health Foundation and led by Jennifer Gosling at the London School of Hygiene and Tropical Medicine. The project is examining quality improvement work being undertaken in general practice, with a focus on the role of practice managers. This will include study of the practice manager population: who they are, their responsibilities, length of service, training and so forth. Research is also under way on another neglected group in the general practice workforce - the GP receptionist.

This is being led by a team at the Health Services Management Centre at the University of Birmingham. The NHS has been slow to embrace the diversity and inclusion of leadership that research evidence emphasises as vital to ensuring appropriate, compassionate and modern management and leadership for caring professions and services. Primary care has its own particular history and management and leadership dynamics, but they are no less gendered than those of NHS Trusts and Foundation Trusts. As primary care moves to embrace the General Practice Forward View15 and associated new models of care, it has an unrivalled opportunity to offer new leadership and management roles to its clinical and practice management community, and to capitalise on the diversity of this population, doing all it can to avoid falling into the trap of a prevailing macho and unhealthy NHS management culture.

\section{References}

1. HSJ (2017) Women Leaders network. www.hsj.co.uk/topics/workforce/women-leaders-network (accessed 23 January 2017)

2. Kline R (2014) The 'snowy white peaks' of the NHS: a survey of discrimination in governance and leadership and the potential impact on patient care in London and England. www.england.nhs.uk/wpcontent/uploads/2014/08/edc7-0514.pdf (accessed 23 January 2017)

3. NHS Leadership Academy (2017) Inclusion, equality and diversity. www.leadershipacademy.nhs.uk/resources/inclusion-equality-and-diversity/ (accessed 23 January 2017)

4. Huntington J (1995) Managing the Practice: Whose Business? Radcliffe Publishing, Oxford

5. Grimshaw J, Youngs H (1994) Towards better practice management: a national survey of Scottish general practice management. J Manag Med 8(2): 56-64

6. NHS Employers (2016) Gender in the NHS.

www.nhsemployers.org/ /media/Employers/Publications/Gender\%20in\%20the\%20NHS.PDF (accessed 23 January 2017)

7. Health and Social Care Information Centre (2014) General and Personal Medical Services: England 2003-2013. http://content.digital.nhs.uk/catalogue/PUB13849/nhs-staf-2003-2013-gene-prac-rep.pdf (accessed 23 January 2017)

8. Wood J (2015) The shortage of women leaders does patients a disservice.

www.hsj.co.uk/topics/workforce/women-leaders-network/the-shortage-of-women-leaders-does-patientsa-disservice/7001066.article (accessed 23 January 2017)

9. Nuffield Trust (2014) Is general practice in crisis? www.nuffieldtrust.org.uk/sites/files/nuffield/publication/general_practice_in_crisis_3.pdf and 
http://campaign.r20.constantcontact.com/render?m=1102665899193\&ca=71b1a83d-5c62-48a9-abe821a1ead610e1 (accessed 23 January 2017)

10. Newman P (2015) NHS Women in Leadership: Plan for Action. NHS Confederation, 2015

11. Mennerick $L$ (1975) Organizational structuring of sex roles in a nonstereotyped industry, Administrative Science Quarterly 20(4): 570-86

12. Smith J, Goodwin N (2006) Towards managed primary care : the role and experience of primary care organizations. Ashgate, Surrey

13. First Practice Management (2016) Practice Manager Salary Survey 2016.

www.firstpracticemanagement.co.uk/blog/posts/practice-manager-salary-survey-2016-results-the-genderpay-gap-revealed/ (accessed 23 January 2017)

14. Smith J (2014) Thirty years, little progress: women in NHS management.

www.nuffieldtrust.org.uk/blog/thirty-years-little-progress-why-we-still-need-talk-about-women-nhs-

management (accessed 23 January 2017)

15. NHS England (2016) General Practice Forward View. www.england.nhs.uk/wp-

content/uploads/2016/04/gpfv.pdf (accessed 23 January 2017)

\section{Copyright notice:}

This document is the Accepted Manuscript version of a Published Work that appeared in final form in Practice Management, copyright (c) MA Healthcare, after peer review and technical editing by the publisher. 